\title{
Una «mirada» sobre el Boletín de la U.I.E
}

\section{María fernanda Mancebo}

\section{Abstract}

The objective of this article is to contribute to the recovery of the Culture of the Exile, using in this case the Boletín de la Union de Intelectuales [si es ese el nombre completo de la publicación]. After describing its main characteristics and collaborators, the paper focuses on the Boletin's political attitude : anti-francoist and anti-fascist, but non-partisan. Another important feature is the Boletin's denouncement of both francoist repression of the "internal Exile" and falangist control over Spanish education institutions, from primary schools to universities.

\section{Resumen}

El artículo pretende contribuir a la recuperación de la cultura del exilio, expresada en este caso a través del Boletín de la Unión de Intelectuales. Tras una descripción obligada de su morfología esencial y colaboradores, entre los posibles temas a abordar se destaca la actitud política del Boletín, antifranquista y antifascista, pero no partidista. Y la denuncia de la represión franquista sobre el exilio interior con las directrices falangistas desde la universidad a la escuela.

\section{Citer ce document / Cite this document :}

Mancebo María fernanda. Una «mirada» sobre el Boletín de la U.I.E. In: Exils et migrations ibériques au XXe siècle, $\mathrm{n}^{\circ} 3-4$, 1997. pp. 87-101;

doi : https://doi.org/10.3406/emixx.1997.1098

https://www.persee.fr/doc/emixx_1245-2300_1997_num_2_3_1098

Fichier pdf généré le 28/08/2018 


\title{
Una «mirada» sobre el Boletín de la U.I.E.
}

\author{
$M^{a}$ Fernanda Mancebo \\ Universidad de Valencia
}

\begin{abstract}
El artículo pretende contribuir a la recuperación de la cultura del exilio, expresada en este caso a través del Boletín de la Unión de Intelectuales. Tras una descripción obligada de su morfología esencial y colaboradores, entre los posibles temas a abordar se destaca la actitud política del Boletín, antifranquista y antifascista, pero no partidista. Y la denuncia de la represión franquista sobre el exilio interior con las directrices falangistas desde la universidad a la escuela.

The objective of this article is to contribute to the recovery of the Culture of the Exile, using in this case the Boletin de la Union de Intelectuales [si es ese el nombre completo de la publicacion]. After describing its main characteristics and collaborators, the paper focuses on the Boletin's political attitude: anti-francoist and anti-fascist, but non-partisan. Another important feature is the Boletin's denouncement of both francoist repression of the "internal Exile" and falangist control over Spanish education institutions, from primary schools to universities.
\end{abstract}

A diferencia de otras disciplinas, la historia no sólo tolera sino que reclama la pluralidad de interpretaciones.

La diversidad de puntos de vista no impide que cada uno posea relativa validez y que todos, de ésta o aquélla manera, se completen unos a otros. Incluso las contradicciones y oposiciones son fecundas y contribuyen a la visión de conjunto. La historia no es incoherente pero sí hostil a las explicaciones únicas y totales.

O. Paz. Hombres en su siglo, p. 47

Estas palabras fueron leídas en noviembre de 1979 en una reunión que conmemoraba la llegada de los republicanos españoles a México. El hecho de que Paz no sea historiador y de que personalmente no coincida con muchas de sus «interpretaciones», no invalida su autoridad para iniciar este texto. 
Desde 1976, a partir de la obra dirigida por José Luis Abellán, la cultura del exilio está siendo objeto de diversas investigaciones que completan aquel panorama esbozado por Manuel Andujar, Antonio Risco, el propio Abellán y otros ${ }^{1}$.

Mediante un mejor conocimiento y reflexión sobre las fuentes, en ocasiones en ediciones facsimilares que facilitan el acceso, los historiadores de la cultura van cumpliendo aquella tarea vasta y exigente que enunciaban los primeros estudiosos: «subrayar lo que corresponde al movimiento cultural que propició la II República y que lanzado fue al exilio» ${ }^{2}$. Y analizar y valorar lo que el exilio añadió o restó a la obra de aquellos escritores, poetas, científicos y artistas que hubieron de desenvolverse en circunstancias tan adversas bien en Europa, bien al otro lado del Atlántico. Sin olvidar desde luego las manifestaciones de una cultura popular socialista, anarquista - que aún más laboriosamente va saliendo a luz.

Con este trabajo pretendo profundizar en el estudio del Boletín de la UIE que tangencialmente habíamos utilizado para presentar la actividad políticocultural de Corpus Barga en el exilio ${ }^{3}$

La lectura que habíamos hecho de esta revista nos llevaba, por un lado, a coincidir con la opinión de Antonio Risco que precisa su importancia entre las publicaciones en Francia. Y, por otro, quiero subrayar que, pese a su proclamado apartidismo y su orientación eminentemente cultural, el Boletín mantuvo implícita y en ocasiones explícitamente una clara línea de compromiso político, bien que no militante, que lo marcó a lo largo de sus años de existencia, tal como ocurrió con Independencia, Ibérica, el Boletín de los intelectuales de México, etc.

Así pues, mi trabajo constará de dos partes: una presentación sucinta de su morfología esencial y el estudio de unos temas que en el trabajo sobre Corpus Barga quedaron apuntados únicamente.

\section{El Boletín. Morfología. Financiación. Secciones.}

El Boletín (1944-1948), no aparece en los primeros momentos del exilio. Es evidente que entre 1939 y 1944, las publicaciones españolas, en ocasiones clandestinas, tienen todas un carácter de «urgencia», de «circunstancias», tal como ocurrió durante la guerra civil en la zona republicana. Algunas son efimeras y las más son órganos de expresión de

\footnotetext{
1 VV.AA. El exilio español de 1939, 6 vols., Taurus, Madrid, 1976, especialmente los volúmenes III, IV y V.

${ }^{2}$ Id. M. Andujar, A. Risco, «Crónica de la emigración en las revistas», III, p. 13.

${ }^{3} \mathrm{M}^{\mathrm{a}}$. F. Mancebo, $\mathrm{M}^{\mathrm{a}}$. V. López González, «El exilio francés de Corpus Barga», comunicación presentada al I Congreso del Exilio Literario, Barcelona, 1995, Las Actas están en prensa.
} 
partidos y organismos de ayuda ${ }^{4}$. A excepción de la Revista de Catalunya, las publicaciones cultural/literarias periódicas sólo pueden aparecer en los momentos finales de la guerra mundial, cuando van cediendo las trágicas circunstancias que la rodearon y la emigración empieza a asentarse en puntos geográficos concretos: Toulouse, Marsella, París... No podía ser de otro modo, pues ¿cómo habrían subsistido los órganos de expresión desde 1939, con la obligada incorporación a las compañías de trabajo, el alistamiento a la legión extranjera o la participación en la Resistencia? ${ }^{3}$.

Es cierto que todo el que pudo se fue de aquella Francia que rechazaba a «los rojos»y pronto iba a ser invadida por los nazis. ${ }^{6}$. Pero la tradición liberal y republicana francesa, aunque en los primeros momentos quedará desdibujada y desmitificada, pronto «enganchó» a los españoles que allí quedaron, pues eran conscientes de que al luchar por Francia lo hacían también contra el enemigo común: el nazi-fascismo. En cuanto a los franceses, «la participación de los españoles en la guerra produjo un cambio en la imagen que del exiliado se había forjado una parte de la sociedad»? En lo que concierne a la ausencia de reconocimiento oficial de la República en el exilio (sí lo hizo de manera oficiosa), a pesar de las presiones de partidos y sindicatos de izquierda, más se debió a la actitud de Estados Unidos e Inglaterra, que no permitieron que prosperara la condena de la ONU hacia el régimen de Franco ${ }^{8}$.

\footnotetext{
${ }^{4}$ No he podido consultar la importante tesis de Geneviève Dreyfus-Armand. Sin embargo coincido con la caracterización que hace de la prensa y en su apreciación de que este tema «est une histoire en cours d'élaboration», ampliando su idea de la participación de los españoles en la resistencia francesa, a todo lo referente a la prensa y publicaciones de los exiliados. G. Dreyfus-Armand, « La presse clandestine espagnole en France pendant la Seconde Guerre mondiale. Clandestine dans la clandestinité », Españoles en Francia, 19361946, Coloquio Internacional, mayo 1991, Salamanca, pp. 263-279. El Boletin de la U.I.E. también ha sido tratado por Geneviève Dreyfus-Armand en "Cultures d'exil au travers de la presse de l'émigration espagnole en France. 1938-1946". Y Serge Salaün en "Les voix de l'exil. La poésie espagnole en France: 1938-1946". Ambos artículos en Exils et migration. Italiens et Espagnols en France: 1938-1946. Sous la direction de Pierre Milza et Denis Peschanski, Ed. L'Harmattan, París, 1994.

5 A. Alted, «Franco y el régimen: imágenes desde el exilio», Historia contemporánea, Universidad de Alicante, $\mathrm{n}^{\circ}$ s. 8-9 (1991-1992), pp. 149-176; J. $\mathrm{M}^{\mathrm{a}}$ del Valle, Las instituciones de la República española en el exilio, Ruedo Ibérico, París, 1976.

${ }^{6}$ A. Sánchez Vázquez, Del exilio en México, Recuerdos y reflexiones, México, 1990; SINAIA, Diario de la primera expedición de republicanos españoles a México. Edición facsimilar. Presentación y epílogo de Adolfo Sánchez Vázquez, Cincuentenario de la expedición, México, 1989.

7 A. Alted, op. cit., p. 155. G. Dreyfus-Armand \&Les réfugiés républicains au coeur des relations franco-espagnoles, 1945-1962». Relations internationals, $\mathrm{n}^{\circ} 74$, eté 1993, pp. 153169 , especialmente pp. 156 y 158.

${ }^{8}$ El 4 de marzo de 1946 la Nota tripartita asume la declaración de la Conferencia de Postdam (julio-agosto 1945) en el sentido de que el gobierno español (de Franco), no reunía las
} 
Volviendo al Boletín. Se inicia en noviembre de 1944, con un ejemplar en edición roneotipada, que se refunde en el primero de la colección en diciembre. En la portada un Antonio Machado ya anciano recuerda su reciente desaparición -un Machado que, con García Lorca y Miguel Hernández constituirán la iconografía poética y mítica del destierro-.

Consta de cuarenta y siete números, los tres últimos de agosto, septiembre y octubre de 1948, en veintinueve entregas, ya que algunos son dobles o triples, índice de la escasez de medios y dificultad de la empresa. Es una publicación de periodicidad mensual, modesta, pero no insensible a una estética aceptable. Como seña de identidad incluye en todos los números igual composición en el título, con una viñeta anónima que hace alusión a todas las manifestaciones intelectual/culturales que pretende abarcar: letras, ciencias, música y artes plásticas. La política, que es el tema prioritario que voy a tratar está implícita, aunque no tenga siempre una expresión externa clara. En este sentido, cabe preguntarse: ¿qué cultura no es política?, además, como dice Risco «esas publicaciones... no son 'neutras', no nacen por generación espontánea $o$ por puro afán especulador ${ }^{9}$. Con más razón ésta que, pese a su proclamado apoliticismo o apartidismo, toma postura en varias ocasiones a lo largo de los cuatro años de existencia ${ }^{10}$.

condiciones necesarias para formar parte de la ONU. Actitud que continuaba la propuesta del embajador de México en la Conferencia de San Francisco, de condena moral al régimen de Franco y su repudio como miembro de la ONU (19 junio 1945). El Memorándum que preparó la Junta Española de Liberación (JEL) se encuentra extractado en J. $\mathrm{M}^{\mathrm{a}}$ del Valle, Las Instituciones... p. 91-102, así como la defensa que el embajador de México Luis Quintanilla hizo en la Conferencia de San Francisco de la propuesta de enmienda española en el sentido de que Franco (fascista) no debía figurar en la ONU. pp. 110-112. No se va mucho más allá, pero el cambio de actitud de Francia se refleja en la imagen que los exiliados españoles reconstruyen de la misma y las permite integrarse en la sociedad francesa. Véase también E. Moradiellos, La perfidia de Albión. El gobierno británico y la guerra civil española, S. XXI Edit., marzo, 1996. A estas alturas quedaba muy claro que una España republicana o una República española en el exilio no interesaba a las grandes potencias ganadoras de la guerra.

9 A. Risco, «Las revistas culturales y literarias de los exiliados españoles en Francia», VV.AA., El exilio español de 1939, III, p. 97.

${ }^{10}$ Tampoco fue propiamente política Ibérica (1953-1974), como antes decía, cuya defensa de la República y antifranquismo queda evidente. Véase el documentado estudio de A. Alted, «La cultura política del republicanismo liberal español en el exilio. Un ensayo de caracterización a través de la Revista Ibérica (1953-1974)». En Medio siglo de cultura: Exilio, Franquismo y Democracia (1939-1989). Manuel L. Abellan (ed.). Cuadernos interdisciplinarios de estudios literarios, Vol I, $n^{\circ}$ 2, Otoño 1989, pp. 237-263. Sin los Apéndices, publicado en Cuadernos republicanos, 3 (abril, 1990), pp. 35-53. Ni España peregrina, Revista de la Junta de Cultura Española, ed. facsímil, Alejandro Finisterre, editor, México, 1977. Romance o Litoral. Las Españas y Diálogo de Las Españas, dada su mayor duración, 1946-1963, tienen el mismo carácter en principio, «publicación cultural, republicana, enemiga intransigente de lo que Franco encarna...», para luego adquirir un matiz 
Los cuarenta y siete números guardan el mismo formato, pliegos en folio que oscilan entre las ocho páginas, el primero, y doce los tres últimos en conjunto. En algún momento llega a tener dieciséis. En ellos alterna la prosa y la poesía con escasa fotografia y dibujos, éstos, de pintores e ilustradores que permanecieron en Francia -incluso los que salen de los campos de concentración- El valenciano Eduardo Muñoz (Lalo) ${ }^{11}$ colabora en los primeros números con dos episodios del campo de Mauthausen y en el de conmemoración del centenario de Cervantes $\left(\mathrm{n}^{\text {os }} 36\right.$ y 37$)$. Este número es privilegiado, pues tiene dibujos de Joaquín Peinado, Hernando Viñes, Pedro Flores $^{\text {I2 }}$ y Lalo Muñoz, que ilustra los artículos de Félix Montiel y Alvaro de Albornoz.

La práctica carencia de componente gráfico se compensa con títulos algo llamativos y recuadros que tratan de romper la monotonía de letra impresa. Llama la atención la ausencia de Picasso, pues figura entre los cien primeros promotores, aunque sí colabora en exposiciones solidarias con los llegados de los campos, en otras iniciativas y también en España Peregrina, ien México!, ¿Sería la fama o el dinero?. También sorprende que solo dibujen cuatro entre los veintiún pintores-escultores que figuran en la mencionada lista, más los que luego se adhieren. En fin, no tiene la categoría literaria de España Peregrina ni la plástica de Romance.

más político (o politizado), aunque siempre independiente de «cualquier grupo o partido político concreto». A. Alted Vigil, «Las Españas y Diálogo de las Españas. Integración nacional y recuperación de la continuidad de la cultura en el exilio», en N. Sánchez Albornoz (comp.), El destierro español en América. Un trasvase cultural, ICI-5 $5^{\circ}$ Centenario, Madrid, 1991, pp. 219-233. Independencia (1946-1947), con ocho números, tiene carácter parecido y participan en ella bastantes miembros del Boletín: Corpus Barga, Giner Pantoja, Gómez Nadal, Martínez Risco, junto a algunos nuevos: Alberti, Azcárate, Jorge Semprún.

11 Eduardo Muñoz Orts (1907-1964), cursó estudios de derecho y luego ingresó en la escuela de bellas artes de S. Carlos, donde se afilió a la FUE. Fue miembro destacado del grupo de teatro El Buho. Ingresó en el partido comunista y militó en la Alianza de Intelectuales para Defensa de la Cultura. Se enroló voluntario en un batallón alpino que combatía en el frente de Aragón y pasó a Francia. Internado en Arlés fue movilizado y se incorporó al ejército francés. Luchó en Dunkerke y hecho prisionero se le obligó a trasladarse a pie al campo de exterminio de Mauthausen. Por «su carisma personal y su simpatía logró pronto conseguir la confianza del comandante» que le encargó la decoración de un pabellón de caza. Ayudó muchísimo a sus compañeros y «fue uno de los primeros españoles que enarboló la bandera de la esperanza». Se le confiaron misiones de gran responsabilidad.Después de la liberación (5 de mayo de 1945), llegó a París y fue protegido por Picasso de quien se considera discipulo. Casó con una francesa y murió de leucemia en Issy-les-Molineaux (París) el 10 de mayo de 1964. Esta breve biografia procede de testimonios de diversos amigos suyos de la FUE de Valencia y un suelto aparecido en Hoja del Lunes de Francisco Agramunt Lacruz. Lalo Muñoz también colaboró en Independencia.

${ }^{12}$ Sobre Hernando Viñes, P. Flores y Joaquín Peinado, hay algunas referencias en el Boletín. Incluso ellos escriben reseñas de exposiciones y artículos críticos, o ensayos. Sobre Pedro Flores, J. Ma Giner Pantoja «Crónica de arte», Boletín UIE $n^{\circ} 14$ (enero 1946), p. 6. Sobre Joaquín Peinado, $n^{\circ} 19$ (junio 1946); n²0 (julio 1946); n² 24 (noviembre, 1946). 
El Boletín se financia con suscripciones cuya cuota mínima son cien francos anuales y en el primer número expone:

La Unión de Intelectuales Españoles no cuentan con otros medios de existencia que con los que le procuren sus afiliados y los que vean con simpatía su labor. Pedimos por eso a todos un esfuerzo económico en relación con sus posibilidades para asegurar la vida del BOLETÍN... ${ }^{13}$

En ningún mes figura el precio $\mathrm{y}$ en el mismo primer número se ruega que los donativos sean enviados al -probablemente- domicilio de José $\mathbf{M}^{\mathbf{a}}$ Quiroga Pla (57, rue Sarrette, París, 14 ). En junio de 1945, la sede del Boletín, así como de la U.I.E., se ha trasladado al 36, rue d'Assas, París $6^{\text {e; }}$ la correspondencia debe dirigirse al secretario general adjunto Salvador Bacarisse y el dinero al tesorero José Castro Escudero. Pero en julio-agosto del mismo año, la situación mejora visiblemente. Se ha conseguido una subvención oficial de 30.000 francos anuales y la U.I.E. se ha instalado en el local cedido por el Institut Prophylactique, con un funcionario en la secretaría. Y se anuncia que el Boletín será mensual. El final de la guerra y la posible/probable caída del régimen franquista en España repercuten en una mejora de las condiciones de vida de la resistencia española en Francia. La ayuda que los españoles prestaron a la resistencia francesa y a la lucha contra el nazismo y el fin de la tensión que supuso la guerra permiten una mejor relación entre la Francia liberada y el grupo de exiliados, según hemos visto. En esta misma etapa (1945) se arbitra una nueva fórmula para contribuir al mantenimiento de la revista, debida seguramente al aumento de afiliación y dificultades económicas de los españoles. Se establece una cuota con una entrada de $50 \mathrm{~F}$ y aportación ordinaria mensual de $20 \mathrm{~F}$. Más adelante (abril 1946), se advierte que un número suelto vale $10 \mathrm{~F}$. La suscripción anual se mantiene en $100 \mathrm{~F}$. Quizá antes algunos se entregaban como obsequio.

En 1947 parece que está en camino de remontar las dificultades económicas, o al menos eso se dice en la Conferencia de 11 de mayo. Sin embargo, un año más tarde, tras una llamada a los suscriptores y simpatizantes, «el Boletin de la U.I.E. necesita vuestra ayuda», dejó de salir. Fueron cuatro años plagados de problemas, frente a uno que salió, España Peregrina, (1940-41), uno de Romance (1940-41), y cinco del Boletín de la U.I.E. (1956-1961) todas ellas en México, donde había muchas más posibilidades. En cuanto a las francesas, España Republicana vive también cuatro años, aunque tiene el apoyo del partido. Independencia dos, con ocho números, y el resto son de vida más corta. ${ }^{14}$

${ }^{13}$ Boletín UIE, $\mathrm{n}^{\circ} 1$, p. 6.

${ }^{14}$ Confróntese F. Caudet, El exilio republicano en México. Las revistas literarias (19391971), Fundación Banco Exterior, Madrid, 1992 , y A. Risco, «Las revistas culturales...». Por establecer una comparación, a los trabajadores de las Compañías se les pagaba 0 $50 \mathrm{ctms}$. de franco. Y en $1938 \mathrm{La}$ Voz de Madrid, cuesta 3 meses, 12 francos, y la suscripción anual es de 
El Boletin es, ante todo, órgano de la U.I.E. y, por ello, dedica una parte importante a reseñar su organización, actividades, iniciativas y puntos de vista. Se advierte, con el transcurso de los años, que se va estructurando, pero conserva desde el principio el patrón clásico. Un editorial sin firma, trabajos en prosa y poemas firmados. Una nutrida sección «Actividades de la U.I.E.» que reseña ampliamente la gestión de la Unión: reuniones extraordinarias, plenos, juntas o asambleas generales. $\mathrm{Y}$ de las distintas secciones, ampliadas más tarde con pedagogía ( $\mathrm{n}^{\text {os }} 8$ y 9 , agosto 1945), y ciencias jurídicas y sociales ( ${ }^{\text {os }} 28$ y 29 , marzo 1947). Hay colaboraciones diversas y un tema más amplio que se dedica al cine en el primer número, debido a la pluma de Guillermo Fernández, en el segundo al arte, «La función social del arte», de José Castro Escudero, en el que se observa la continuación de las obsesiones de la guerra. Otros números lo dedican a cultura «Las bibliotecas generales en España», de Teresa Andrés, y poesía «Medio siglo de poesía española» de José $M^{\mathrm{a}}$ Quiroga. ${ }^{15}$ A partir del $\mathrm{n}^{\circ} 2$ las «Actividades» pasan a llamarse «Crónica» ${ }^{16}$.

Alguna noticia recibe un tratamiento especial en recuadro aparte, destacada; generalmente necrológicas de exiliados relevantes: «Don Blas Cabrera ha muerto» ( ${ }^{\circ s} 8$ y 9); «José Castillejo» $\left(n^{o s} 10\right.$ y 11); Francisco Largo Caballero ( $\left.{ }^{\circ} 17\right)$; Teresa Andrés y Demófilo de Buen ( $\left.\mathrm{n}^{\circ} 20\right)$; Manuel de Falla merece un número casi entero $\left(\mathrm{n}^{\circ} 25\right)$. Y en el mismo, Corpus Barga recoge sentidamente la muerte de Nusch Eluard, con un elogio del matrimonio Eluard, grandes amigos de España. Alberto Vela escribe sobre Marcelino Domingo ( $n^{\text {os }} 28$ y 29). Y sobre José Ontañón hay un artículo de Sebastián Lafuente ( $n^{\text {os }} 45,46$ y 47 ). Es por tanto una fuente interesante para el exilio en general, sin distinción de partido o actividad.

También como fuente documental recoge, resaltadas, manifestaciones solemnes por algún motivo especial que no creo quedaran en meras declaraciones de principios. Así el Manifiesto, en el $\mathrm{n}^{\circ} 15^{17}$. Igualmente, el Boletín saluda a Diego Martínez Barrio -presidente interino de la República en el exilio- a su llegada a París $\left(n^{\circ} 16, p .1\right)$. Y anuncia la refundación de la «Unión de Profesores Universitarios Españoles en el Extranjero» (luego

40FF. Portada reproducida en G. Dreyfus-Armand, «La presse de l'émigration en France de 1939 à 1944, Contre vents et marées», Plages d'exil, BDIC, 1989, pp. 185-196. Independencia, vale 8 francos y los números finales 7 y 8 , han subido a 12 francos.

${ }^{15}$ Para mayor información A. Risco «Las revistas culturales...».

${ }^{16}$ Como ejemplo la «Crónica» del $n^{\circ} 4$, comprende, «Relación de nuevos afiliados»; «Pleno de la UIE de abril (1945)»; «Homenaje a los intelectuales deportados»; «El monumento a Antonio Machado»; «La reconstitución de la FETE»; Las conferencias de 'Unidad y Lucha'; Cultura catalana.

${ }^{17}$ Boletin UIE, $\mathrm{n}^{\circ}$ 15, (febrero 1946), p. 2. 
«Exilio»), (UPUEE) en Francia, encargada a Manuel Martínez Risco, desde México ${ }^{18}$.

Sin el carácter de secciones fijas aparecen de vez en cuando reseñas y críticas de libros y revistas, con frecuencia a cargo de Emili Gómez Nadal, y un apartado de «Bibliografía», pero no llega a tener la envergadura de la sección bibliográfica de España Peregrina, a cargo de Agustín Millares Carlo. ${ }^{19}$

La nómina de colaboradores es amplia, pero son puntales máximos José $M^{a}$ Quiroga Plá, José Castro Escudero, José $\mathbf{M}^{\mathrm{a}}$ Giner Pantoja, José $\mathbf{M}^{\mathrm{a}}$ Semprún Gurrea, Jerónimo Chicharro de León, Manuel Martínez Risco, Corpus Barga y el mismo Gómez Nadal. La representación nacionalista catalana y vasca, si bien se enuncia en principio: Rafael Tasis y F. J. de Landaburu, después se difumina. Tampoco es relevante la conexión con los intelectuales franceses del momento, salvo los hispanistas Marcel Bataillon o Jean Cassou.

En definitiva el Boletín es una plataforma, más cultural que política, desde luego, pero que sirvió de resonancia para las voces acalladas del interior, así como para establecer contacto con los exiliados de las Américas y los radicados en Francia. Paso ahora a examinar algunos temas a través de las editoriales y artículos de fondo que servirán para ilustrar su línea político-cultural.

\section{La actitud política del Boletín.}

En el editorial del $\mathrm{n}^{\circ} 1$, dirigido a los intelectuales españoles residentes en Francia se dice:

18 Martínez Barrio fue investido presidente de la República el 17-VIII-1945 en México. Descripción de la solemne ceremonia, J. $\mathrm{M}^{\mathrm{a}}$. del Valle. Las instituciones... p. 117. Debe haber alguna confusión en el Boletín respecto a su condición de interino. Para la UPUEE, $M^{\mathbf{a}} \mathrm{F}$. Mancebo, «La oposición intelectual en el exilio. La reunión de La Habana, (septiembreoctubre 1943), La oposición al régimen de Franco, J. Tusell, A. Alted, A. Mateos (coord.), 2 vols., Madrid, 1990, II, pp. 57-72. La candidatura, propuesta por la Junta general para la nueva directiva, estaba integrada por: Presidente: Rafael Altamira y Crevea. Secretario: Francisco Giral. Vicepresidentes: Manuel Márquez y Mariano Ruiz-Funes. Secretarios adjuntos: Manuel de Rivas Cherif; José Torres Blanco; Julián Calvo; Bibiano F. Osorio Tafall. Tesorero: Manuel Sánchez Sarto. Consejeros (representantes de las cinco facultades). Pedro Bosch-Gimpera (F y L); Joaquín Xirau (F y L); Cándido Bolívar (C); Honorato de Castro (C); Pedro Carrasco Garrorena (C); Gabriel Franco (D); Antonio Sacristán (D); José Puche (M); Alejandro Otero (M); Julio Bejarano (M). Antonio Madinaveitia (F).

19 El «Registro bibliográfico (1939-1940)», es un ambicioso proyecto de recoger la producción escrita del exilio, clarificado por materias, desde el $n^{\circ} 2$. Llego a tener ochocientos cincuenta y seis títulos. Se exceptuaba lo referido a la guerra civil que iría según el proyecto en registro aparte. Esta magna Biblioteca hispánica, fue descrita con todo detalle por Juan Vicens, España Peregrina, n 7, pp. 17-21. 
Idéntico espíritu nos anima a todos, por encima de cualquier ideario político y social, supeditándolo todo al derrocamiento de Franco y la Falange, a la reconquista de España y de su independencia y libertades... la U.I.E. tiene un cometido específico: agrupar, como su mismo título indica, eficazmente a todos los compañeros, compatriotas nuestros, que en el destierro de España tengan conciencia de los deberes a que les obliga doblemente para con la patria esclavizada su condición de españoles libres y de intelectuales... La libertad y la cultura de España están en juego.

Y continúa expresando que esto es el inicio a la espera de «la posibilidad material de unir (a la empresa) a nuestros hermanos, actualmente en América, África, Inglaterra y la U.R.S.S. y, más adelante, en España...». Por tanto, en principio, no hay una clara determinación de conectar con los intelectuales franceses aunque, por supuesto, la actitud sea completamente abierta hacia ellos.

En cuanto a la actitud política, el Boletín, igual que la Junta de Cultura, con España Peregrina, se planteaba crear entre los intelectuales repartidos entre los diferentes países, un espíritu verdadero de solidaridad, independiente de todo partidismo político, así como «Fue consigna (de la Junta en aquella histórica Buhardilla) la declaración de guerra a la baja política generadora de división» puesto que «La politica de partidos, asiéndose a cuantos incidentes a ello se prestaran, habría de dividir a los emigrados con las actuaciones personales de quienes fueron responsables en buena parte de la derrota ${ }^{20}$ y ello favorecía a los «mortales enemigos»-el franquismo y el fascismo-.

Aquí se entiende que la Junta planteaba una actitud política antifranquista, aunque no desde luego partidista. Pero, en fin, todo esto se refiere a la Junta de Cultura y, aunque algunos miembros coincidían en una y otra organización y publicación (Junta y Unión; España Peregrina y Boletín), veamos que ocurre con este último.

El Boletín critica «con vehemencia» la política de partidos, pero sus razones son del mismo tipo que las de la Junta. Es una hipótesis que aún hoy se plantea cuando se hace la historia de las desavenencias entre «negrinistas», «prietistas» y «caballeristas»; «socialistas» y «comunistas» y «anarquistas»; de «republicanos» de una u otra tendencia, y el resto. Parece claro que se debía tender a la unión sobre bases culturales o políticas, «todas»; por encima y a pesar de los partidos.

En México se plantean los mismos problemas, aunque el exilio en sus diferentes opciones políticas parece que se reconstruye antes o al menos al mismo tiempo que en Francia y en mejores condiciones. Allá resigna Negrín su jefatura de gobierno ante las Cortes (agosto 1945). Se nombra el primer gobierno del exilio, aunque hubieran dificultades, se rehacen los partidos...

${ }^{20} \ll$ Una buhardilla y un Manifiesto», España Peregrina, n 2, p. 78. 
con las disensiones de siempre... hasta en 1959 se produce un movimiento, el ME/59, historiado recientemente por Elena Aub ${ }^{21}$.

La toma de postura política del Boletín se encuentra claramente expresada en el Manifiesto, que he mencionado anteriormente:

Los intelectuales republicanos quieren un gobierno verdaderamente representativo.

Los miembros de la Unión de Intelectuales Españolas reunidos en Asamblea general reglamentaria, aprovechan esta ocasión para dirigir un llamamiento a todos los partidos y organizaciones antifascistas del destierro, para que dejando de lado todo lo que no sea el supremo interés de la libertad de España y de los españoles, constituyan un Gobierno definitivo en el que figuren sin exclusión alguna, la representación de cuantos sectores están dispuestos a luchar por el derrocamiento del régimen de Franco y de Falange. Con el fin de que un Gobierno así formado, pueda dirigir con plena autoridad la lucha, realizar la depuración del aparato del Estado y proceder a la consulta electoral en la que el pueblo español decidirá, libre y democráticamente sus destinos». ${ }^{22}$

Una cita demasiado larga quizá, pero que aclara la postura política de la U.I.E, en su actitud legitimista a ultranza. «Sin exclusión alguna... derrocamiento del régimen de Franco y de Falange». Así como el artículo de I. Quero Morales en el mismo número «Las relaciones franco-españolas a partir de 1914» que termina:

En Londres ha de decidirse próximamente la política conjunta a seguir en relación al Gobierno franquista y al establecimiento de la democracia española, primera víctima internacional del fascismo... A medida que el tiempo pasa, la posición internacional de Franco se debilita y la de los republicanos españoles se refuerza...

Estamos en febrero de 1946 y, naturalmente, el Boletín expresa la euforia de la Nota tripartita de primeros de marzo con la condena de la ONU al régimen de Franco, reforzada en las reuniones de septiembre a diciembre. Desde luego no llama a las armas, pero tampoco es este el objetivo.

${ }^{21}$ E. Aub, Historia del ME/59. Palabras del exilio, 5. Dción. Gral. de Publicaciones del Consejo Nacional para la Cultura y las Artes / INAH. México, 1992. Para el debate sobre la estricta legalidad de la representación de la República en el exilio, entre Negrín y la Diputación permanente de las Cortes, véase: $M$. Tuñón de Lara, R. Miralles y B. N. Díaz Chico, Juan Negrin López. El hombre necesario, Gobierno de Canarias, Las Palmas, 1991, p. 149 y ss.

${ }^{22}$ Boletin UIE, $\mathrm{n}^{\circ} 15, \mathrm{p} .2$. El subrayado es mío. 


\section{El conocimiento del exilio interior.}

Junto a artículos y ensayos de toda clase y materias, el aspecto política nunca es dejado de lado en relación al interior de España. Unas veces, varias - contra la Falange, otras, con llamamientos a la ONU en «vehemente protesta contra la supervivencia de un régimen que considera criminal el ejercicio de la inteligencia».

En este caso se refieren a la represión ejercida contra Santiago Alvarez y Sebastián Zapirain $\mathrm{y}$, algo más tarde, contra Isabel Sanz Toledano, licenciada en Filosofía y Letras, condenada a 20 años de presidio, o por la ejecución en Vigo de Julio Rivero, ingeniero; Julio Nava, estudiante, ha sido «torturado por la policía franquista». La denuncia es especialmente fuerte en el caso de $\mathrm{M}^{\mathrm{a}}$ Teresa Toral, doctora en ciencias químicas:

Si la vida de cada patriota español nos es precisa, los intelectuales españoles republicanos nos sentimos especialmente afectados cuando el terror franquista se ensaña particularmente en miembros de nuestra gran familia.

La ola de asesinatos, más o menos «jurídicos», cometidos en España estas últimas semanas (estamos en marzo de 1946 y Francia ha cerrado su frontera con España) y que han conmovido e indignado a las masas democráticas de todo el mundo no ha terminado... Tres mujeres españolas esperan en una cárcel madrileña, el fin de un calvario comenzado en los sótanos del ministerio de la gobernación... Entre (ellas) se encuentra $\mathrm{M}^{\mathrm{a}}$ Teresa Toral... ${ }^{23}$

Algo más adelante se insiste $\mathrm{y}$, en el $\mathrm{n}^{\circ} 27$, publican una nota de la Unión Federal de Estudiantes Hispanos (UFEH), sobre Julio Nava:

...Todo hace suponer el propósito de las autoridades franquistas de suprimir a Julio Nava sin un juicio con garantías procesales; presentando, como otras veces, la trágica realidad del hecho consumado. ${ }^{24}$

En este mismo número, el Boletín denuncia la política de propaganda franquista respecto a Latinoamérica en estos duros términos:

El franquismo, bajo esta envoltura busca establecer puntos de apoyo para el fascismo en América (creación de la cátedra «Ramiro de Maeztu»), fortalecer su red de espionaje y sus enlaces con regímenes como los de Perón, Moriñigo...

En la misma línea se manifiesta Cecilio Palomares con su ensayo «La escuela franquista factor de retraso».

Las denuncias sobre la intervención de la Falange en todos los ámbitos de la vida española son muy frecuentes y tempranas. El artículo de Teresa Andrés «Las bibliotecas generales en España», contiene un apartado Labor de creación de 1931 a 1939 y retroceso falangista. (Boletín, 4, p.4), y en el mismo número se recoge «Los crímenes falangistas contra la cultura», (p.5)

\footnotetext{
${ }^{23}$ Boletín UIE, $\mathrm{n}^{\circ} 16$, p. 12.

${ }^{24}$ Boletín UIE, $\mathrm{n}^{\circ} 27$, p. 12.
} 
En el $\mathrm{n}^{\circ} 18$ (mayo 1946) hay dos artículos que merecen ser reseñados. El primero, de José $\mathrm{M}^{\mathrm{a}}$. Semprún y Gurrea, y el segundo una nota larga en Crónica con el título de «La decadencia cultural de la España franquista».

El de Semprún ${ }^{25}$ es la respuesta al anterior artículo de Corpus Barga «La reconquista de la inteligencia».$^{26} \mathrm{Me}$ interesa destacar del mismo la postura digna del escritor, en reconocimiento de la labor de recuperación de la cultura islámica realizada por Asín Palacios: «porque no vamos a emular la indecencia fascista de suprimir el nombre de quien, con un grupo selecto, llevó adelante la empresa... por el hecho de que luego después, Dios sabe a causa de qué malhadadas circunstancias, fuese a caer al otro lado de la barricada...» Pero sobre todo que, Semprún igual que el resto de escritores o intelectuales, (abusando ya de este calificativo) están absolutamente preocupados por el problema político... solo que no es su cometido el resolverlo. Así dirá en «La reconquista el castillo interior»:

$Y$ lo primero con que nos hallamos al pensar de ese modo en nuestra lamentable situación, es que ella no podrá tener remedio completo mientras no se haya resuelto, con una fórmula o con otra, pero en el sentido de la democracia y de la libertad, el problema político. No corresponde a mi intento ni seguramente al de este Boletín el que nos metamos ahora profundamente en ese terreno intrincado y resbaladizo... los intelectuales, sin que ello signifique alejarse de su misión... tienen que interesarse por la resolución del problema político previo, a lo menos dentro de los términos generales que acabamos de indicar... ese problema, por específicamente político que sea, no se puede solucionar de espaldas a la inteligencia... de todos modos, los intelectuales, mientras se resuelve con ellos o sin ellos (como es posible) ese problema politico, no parece que hayan de estar metidos exclusivamente en las baraúndas de las luchas políticas.

Por su parte, José $\mathrm{M}^{\mathrm{a}}$. Quiroga Plá interviene en este debate, que es posiblemente una de las manifestaciones más interesantes de la Revista. Se identifica con Semprún y Barga pero va un poco más allá. Quiroga reconoce que «El problema de la inteligencia y de la cultura española nos desvela a todos». Y está de acuerdo en que «Hay que empezar a pensar en lo que hay que hacer» pero sobre todo, urge a la acción, subraya que es necesario «empezar a hacer».

Es necesario tener claro lo que debe hacerse al regresar a España, pero propone empezar «por lo que tenemos más cerca». Y reclama una acción política.

Empecemos por crear, por formar aquí esa inteligencia y esa cultura de nuestro pueblo. Y no en rancho aparte, sino entrando en el ruedo; digámoslo de una vez: en

\footnotetext{
${ }^{25}$ José $\mathrm{M}^{\mathrm{a}}$. Semprún y Gurrea, «La reconquista del castillo interior», Boletin UIE, pp. 1-3.

${ }^{26}$ Corpus Barga en este artículo denuncia la situación de España y es una llamada de auxilio tanto para el español exiliado como para la Europa libre. Resalta el carácter nazi de la represión franquista, $\mathrm{y}$, según el pensamiento de estos intelectuales, Barga propugna una actuación cultural-política. Véase la mencionada comunicación en el congreso del GEXEL, cuyos actas están en prensa.
} 
la brega política, dando a esa masa un sentido político, de unidad. No estamos en los pórticos académicos, sino en la emigración... Si los intelectuales no tomamos parte en la reconquista de España y de sus libertades, la otra reconquista, la de la inteligencia, se quedará en agua de borrajas y tema de elegantes disertaciones. ${ }^{27}$

En octubre de 1946, Jesús Izcaray, continuando los artículos de fondo sobre este tema, contesta con todo el ímpetu de su juventud:

El hecho, tremendo en sí es este: enseñanza, libros, prensa, Radio, Teatro, Cine, todo, todo, todo tiende constantemente a hacer válida y a propagar una ideología putrefacta, exhumada de los viejos sepulcros de El Escorial...

Lleguemos al nudo de la cuestión: ¿Hasta qué punto calan estas líneas en el alma de nuestro pueblo?... Nuestro pueblo no aupó el fascismo ni transigió con él ni se resigna a él. Por el contrario luchó y lucha contra él... Le separa del fascismo un foso de sangre...

$\mathrm{Y}$ después de unas acertadas consideraciones sobre la postura que conviene adoptar, especialmente respecto a la juventud intoxicada por «Muchos toros, mucho fútbol, mucha flamenquería y machismo a todo trapo» reconoce que, en ocasiones, «hay demasiado silencio entre nosotros».

\section{Finalmente, termina:}

Yo creo que para encontrar nuestro exacto quehacer ineludible...: todo demócrata español que usa una pluma... es un combatiente del pueblo. Y su deber... está en combatir cosido al pueblo, abrazado a él... ¿quién mejor que nosotros para publicar a la faz del mundo... y dar a conocer su lucha? ${ }^{28}$

En resumen, estos intelectuales, bien analizada la cuestión y aunque se plantean la acción política, consideran que su misión es pensar lo que hay que hacer para «reconquistar la inteligencia española»: su tarea es la de «defender la cultura», otros llevarán a término la labor política con su apoyo, dentro y fuera y, ¿quién puede negar el valor que tuvo la oposición intelectual al franquismo?

Pero es más, en «La decadencia cultural de la España franquista» dan señales de estar perfectamente informados de lo que ocurre en el interior desde el punto de vista político-cultural:

En una Memoria publicada por el Consejo Superior de Investigaciones de Madrid, que ha venido a reemplazar a la Junta para Ampliación de Estudios, se dice que el Gobierno español había pedido su colaboración al Gobierno del Reich... Sabemos que el Instituto Rockfeller, completamente desnaturalizado, esta dirigido por un farmacéutico octogenario; ...El Cajal... por un ingeniero agrónomo... Se

27 A. Risco. Al transcribir este texto lo atribuye a Herrera Petere, con lo que elabora una polémica a ambos lados del Atlántico que, a mi juicio, no existió. El testimonio de E. Gómez Nadal que también aduce, admite otra lectura. Véase la comunicación citada en nota 3.

28 Jesús Izcaray. «Franco y su huella o el cautiverio de la inteligencia española». Boletín, UIE, n²3, (diciembre, 1946), p. 12. El subrayado es mío. 
comprende bien que tengan falta de astrónomos; Carrasco, Risco, Puig y otros están en el extranjero... el padre Rodes... murió misteriosamente separado de su Observatorio del Ebro...

Y por si esto fuera poco, el número 27 (febrero 1947) la U.I.E. responde a la Unión de Intelectuales Libres del interior con un escrito que comienza...

Con emoción raramente igualada hemos recibido el mensaje que vuestra Unión de Intelectuales dirige a los gobiernos y pueblos extranjeros, desde nuestra patria abrumada por el terror y la vergüenza del régimen franquista, última supervivencia descarada del fascismo en el mundo.

\section{Y termina:}

Por lo que... toca a la Unión de Intelectuales Españoles en Francia, cuanto somos y podemos como tales intelectuales, puesto está al servicio de nuestra España republicana...

En fin, en la Crónica del mismo número, la sección En la España franquista, se da cuenta de una pastoral del obispo de Orense en favor del reconocimiento de los títulos de bachiller otorgados por los colegios religiosos; de una intervención de Gregorio Marañón, «al servicio de...» en la facultad franquista de ciencias políticas y económicas: «A su derecha se sentó el decano, 'divisionario azul' y eminencia gris del régimen, Sr. Castiella». Así como un suelto, «Los 'intelectuales' del régimen opinan», en el que aluden a Pedro Font, Nicolás González Ruiz, Pemán, Montes, etc., y desde el punto de vista político, Esteban Bilbao. Por último, comunican la creciente difusión de Demócrito «nuestro colega hermano de la clandestinidad».

En el $\mathrm{n}^{\circ}$ doble 28-29 (marzo-abril 1947), nueva referencia a la Unión de Intelectuales Libres.

A despecho de las medidas policíacas reforzadas durante los últimos meses, la difusión de Demócrito y Cuadernos de Estudio, órganos de la U.I.L., adquieren cada día mayor extensión. Hasta nosotros llegan noticias de la actividad infatigable de los intelectuales del interior... ${ }^{29}$

${ }^{29}$ Bien es cierto que desde la llegada a Paris de Manuel Tunón de Lara (diciembre 1946) comunican más intimamente los intelectuales del interior con los del exterior. Para esta y otras noticias remito a Manuel Tuñón de Lara. Maestro de historiadores, Catálogo de la exposición del mismo nombre. Coordinados ambos por José Luis de la Granja Sainz, Bilbao, Madrid, 1994, pp. 63 ss., y «Sombra antigua de Manolo Tuñón» de Eduardo Haro Tecglen, pp. 73-76, en la misma publicación. La noticia de que Tuñón sacó el Manifiesto de la UIE, firmado por él, que fue difundido por las UIE de Francia y México en Manuel Tuñón de Lara. El compromiso con la historia. Su vida y obra. Edición al cuidado de J. L. de la Granja y A. Reig, Bilbao, 1993, p. 60. 


\section{Conclusión.}

En resumen, y por todo lo expuesto, considero el Boletín, como un modelo de lo que significaron la mayor parte de las publicaciones culturales del exilio republicano español. No fueron, en su mayoría, instrumento de los partidos, ni en Latinoamérica ni en Francia, ni en los Estados Unidos. No se decantaron por una política específica y dejaron de lado en sus páginas las disensiones que dividían y esterilizaban a los exiliados. No creo que existan grandes diferencias ideológicas entre la producción cultural de más allá y más acá del Atlántico. Otra cosa sería su calidad.

El objetivo de todas ellas era la recuperación y reconstrucción de una «cultura» que había comenzado en la España de la República y se había quebrado en la guerra y postguerra. Una cultura -que en ocasiones pasaba por planteamientos políticos- que los reafirmase en su identidad como colectivo, y es aquí donde habrá que situar su compromiso político desde su condición de exiliados conscientes de su escaso poder.

Unas publicaciones de mayor o menor calidad literaria y poética pero contrarias totalmente al régimen de opresión y dictadura existente en España, y defensoras con su pluma de la salvaguarda de unas libertades y de un régimen de democracia.

Como escriben en el último número del Boletín en respuesta al llamamiento de la Agrupación Guerrillera de Levante y Aragón:

...Jamás hemos dudado nosotros de que la salvación de la cultura de nuestra patria, de la que somos servidores y por la que, en la medida de nuestras fuerzas, seguimos laborando en el destierro, se halla inseparablemente unida a la lucha por la salvación de la patria misma, de su soberania y sus libertades democráticas, mediante la plena recuperación de la República... 